\title{
Soy que soy
}

I am what I am

A propósito del Libro de reclamaciones de Isaac Goldemberg

\author{
Alejandro Sánchez-Aizcorbe \\ alejosanchez49@hotmail.com \\ Escritor \\ Perú
}

\section{Resumen}

El presente artículo recorre la obra de Isaac Goldemberg, específicamente su texto el Libro de reclamaciones, y cómo éste transita entre el judaísmo y la vida cotidiana de Perú, entre la mitología judía y la cristiana.

Palabras claves: Goldemberg-Perú -judío-Libro de reclamaciones.

\begin{abstract}
The article covers the work of Isaac Goldemberg, specifically its text The Book of Claims, and how it transits between Judaism and everyday life in Peru, between Jewish and Christian mythology.
\end{abstract}

Keywords: Goldemberg -Perú -Jewish -Book of Claims

Goldemberg reflexiona en el poema y el poema reflexiona por él. El Libro de reclamaciones —en adelante el Libro - es un resumen serenamente meditado de su identidad, conflictiva en grado sumo puesto que reúne factores de alto riesgo: el ser peruano, judío, americano, ciudadano del mundo y natural de Chepén, hermoso pueblo situado en el Pacífico Sur. A confesión de parte relevo de prueba: 


\author{
Porque las ideas \\ son bellas \\ es buena la poesía.
}

El bello pensar

La poesía que piensa

$\cdots$

Contra el verso bien dicho

que no dice nada

la bella poesía

sí dice algo

aunque parezca mal dicho

El Libro sintetiza una vida de ser el que se es con todas las sangres, tragedias y éxtasis de la persona antinómica y eudemonista, que según Baron define, entre otros rasgos, la psique de la nación judía, y que distingue el espíritu de la peruanidad en la literatura, comenzando por Huamán Poma, Garcilaso y los cronistas. Se trata pues de una expresión mayor del judaísmo, de la peruanidad de la posguerra, del siglo en curso y de la poesía universal. Como obra de un pensador y poeta — el de Chepén tiene la suerte de ejercer ambos oficios- el Libro se muerde la cola. Pieza perfectamente circular y dialéctica, cuando acaba, comienza, se desdice, se afirma. Al terminar de leer El libro me siento tentado de concebir la Verdad como la coexistencia de fenómenos éticamente tan contradictorios que resulta insoportable aceptarlos y, por tanto, nos obliga a negarla aferrándonos a disyunciones maniqueas, contenidas en ella, que nos aligeran la vida cotidiana pero no resuelven el enigma de la existencia ni el de su sevicia ni el de su grandeza.

Si la revolución renacentista consistió en desplazar el planeta y la humanidad del centro del universo, la revolución actual nos ha colocado en el universo mismo como proyecto finito. Cada vez se torna más difícil fundamentar una teosofía que conciba a un ser superior que 
conduce, juzga, premia y castiga con el paraíso o el averno. Los remanentes religiosos apenas palian la desnudez humana en medio de la mayor riqueza material de la mayor cantidad de gente posible a costa del planeta y en desmedro de nuestra temporalidad. Los ritos religiosos, con sus aparejos y rituales, semejan juegos radicados en la infancia de la especie. Sin embargo, existen y existirán hasta el final. Goldemberg se sitúa en este multilema, se debate entre las mitologías judía, cristiana, quechua. El resultado es un libro de sabiduría donde la belleza y el pensamiento disuenan tanto como armonizan.

Fundiendo las mitologías griega y judeocristiana, el chepeniense halla lo sublime, lo fantástico, lo maligno y aberrante de Occidente y del Medio Oriente. Estos espacios se hallan en un proceso de rápida transformación hacia una Eurasia que, unida por la necesidad de la supervivencia, ya que no hay otro motivo de fondo que una y desuna las formaciones humanas, quizá alcance la excelsitud concebida como la coexistencia amigable de billones de almas, dejando atrás los horrores de la guerra, de la esclavitud, de las masacres, perennes ante nuestros ojos.

Todavía no estoy muerto, pero quisiera reposar en el hueco más hondo, con todos los que nada tienen que ver conmigo.

Comprobar si de verdad se puede amar al desconocido.

Goldemberg reafirma la poesía en su papel de vehículo de conocimiento, sin perder la coquetería versal, patente en las "Décimas, canciones y poemas de amor fino", ejemplo de parsimonia lograda por un poeta que sabe contar las sílabas y rimar con poca o ninguna envidia del Siglo de Oro, pero libre de sus excesos. Deleita reflexionar ambiciosamente aquí, recitar allá, con dulzura, décimas, canciones, y de tal manera continuar la buena costumbre expresada en el epígrafe a "Las diez palabras":

A veces, los versos repetidos generan música; y gran parte de la musicalidad judía surgió de la resonancia de palabras repetidas. 
Goldemberg repite palabras mas no contenidos. Su verso transmite predicados sin antecedentes, nuevo conocimiento, hidalguía existencial, trasciende el tiempo, el empeño de nuestra vida, transfigurándola en detalle de herejía, en impromptu de sátiro, en un sentido del humor atendible por agudo. La parsimonia vertebra el lenguaje de las crematísticas, escatológicas reclamaciones, que plantean una duda inversa a la de Vallejo: Y si después de tantas palabras hay más palabras, ¿qué nos hacemos con ellas?

Los múltiples campos semánticos del Libro cuentan con un friso: el epígrafe se erige en testimonio poético, filosófico, y a la par crea otro libro, otra palabra, otra caligrafía. El mundo de arriba y el mundo de abajo se miran, dialogan.

Partimos de un cielo existente donde un Dios ateo proclama, por boca de Paul Auster, que la errabundia no implica la existencia de una tierra prometida. Sin embargo, Goldemberg la compone en este mundo, en el ámbito de los sueños, donde el menor detalle tiene sentido (Macera), y en el ámbito de la vigilia, que alimenta los sueños y es predicha por ellos, poniendo como testigos conversantes a una pléyade de escritores peruanos y extranjeros. Esto último, debido al continuo conflicto de identidad manifiesto en el Libro, podría formularse de una manera extraña: escritores internacionales y escritores extranjeros, también llamados peruanos, puesto que para nosotros, los que vivimos en exilio voluntario, a veces los compatriotas nos parecen extranjeros. Compleja es la errabundia.

El terco misterio de la vida determina que, aunque de barriga, nos guste vivir porque "itanta vida y jamás!” (Vallejo) La ausencia de futuro genera la persistencia de la mortadela (Dovidjenko). Goldemberg fabula una utopía, denuncia, maldice la distopía actual — ¿sin camino de retorno?-, propugna la vida, elabora el libro de la muerte que ya se anuncia en nuestros cráneos. Poiesis, big bang, teodicea, teología. Somos los creadores de Dios y de los dioses inúmeros. Muestra de ello son las mitologías, exactas a nuestra conducta. La religión brota de la angustia causada por la finitud: Deo facis timor et timor facis Deo. Por eso Goldemberg propone "Reducir a Dios a una sola letra de ningún alfabeto." 
El golpe iracundo del Dios de Vallejo es asimismo el odio que el prójimo siente por uno. Lo teratológico nos aterra porque habita en nosotros. "El hombre honesto conoce el alma de su Bestia; sabe que sus pies son delicados porque no pisan la tierra sino las cabezas de los hombres", parafraseé al estudiar Oncecielos, último poemario de otro poeta mayor, Tulio Mora, y ahora me siento obligado a repetirlo al recorrer el Libro con semejante pavor y regocijo.

Antes que Dios fue poiesis. Dios es tanto "palabra como razón” y

un solo guarismo de ninguna numeración

un solo umbral donde asome Su ningún único rostro.

El héroe decide desaparecer del óleo y entonces "lo más difícil y complejo recién comienza". Ilegibilidad, ininteligibilidad, enigma. Con su abandono del lienzo, Goldemberg inició su éxodo estético, a resultas del cual nos transmite la elegancia del hombre realizado en sí, para sí, para nosotros. En el libro hierve Arguedas, se cuece Vallejo, se cuaja el pensar de decenas de epigrafiados. Sin merecerlo aunque hambriento como de costumbre, soy uno de ellos, y me siento socio en la épica tarea comunal de querer obedecer y muchas más veces desobedecer, sin ser judío, las 613 leyes que regulan la conducta de los judíos y los mandamientos que Dios nuestro Señor transmitió a Moisés para que a su vez se los comunicase a los israelitas y a la humanidad entera, con disidencias atendibles como las del autor del Libro.

Entre las desobediencias, Goldemberg incluye el deseo de la mujer del vecino, y el de compartir la mujer de uno con un deseadísimo y detestado tercero, impecablemente compuesto en "El ángel de los celos":

... viene puntepiés

a meterse en mi cama

Él sabe que no le tengo

ni pizca de ganas

ifuera maricón! 
Pero él no:

le encanta hacerse el payaso

se pinta de puta

$\cdots$

Con una mano me aprieta los huevos

$\ldots$

¡Suéltame mierda!

Él me mira ahogado de la risa

bate sus alas

hace que mi mujer se aparezca calata

...

de un brinco se monta sobre mi mujer

me ordena que les haga la cama

Se acuestan

me invitan a meterme debajo de la sábana

Lentamente, cerrando los ojos

ella mi ángel y yo

nos internamos en un bosque de ramas furiosas

El amor cortesano, vulgar, coprolálico, se da la mano con la muerte, juntos caminan diciendo prosas valsíferas que evocan la figura gemebunda de Felipe Pinglo y la cadencia licenciosa del vals peruano. El criollismo valetudinario marca la pauta en un área importante de la complicada identidad de la persona que se nos da a conocer en el Libro. Una persona heteróclita que no se sabe bien quién es porque es nosotros.

"Toda vida es un compromiso irreconciliable entre contradicciones lógicas, y todo monólogo interior que refleja la realidad acaba en antinomias inconciliables. Pero la mente judía, siguiendo la lógica de sus extraordinarios destinos, aparece como una cadena ininterrumpida de antinomias y paradojas", afirma Baron $(I, 20)$. Esto se cristaliza en "Nuncas", último poema del Libro, donde el autor no se perdona a sí mismo ni deja por ello de amarse, ni de amar y 
condenar a sus seres queridos. La vil, excelsa condición descrita en dicho poema, al que calza como horma de su zapato el epígrafe de Vallejo, se delata sola:

Nunca dejas de amar a ninguno de los que te amaron, si bien por un segundo, ni de enjuiciar sus lealtades.

Nunca dejas de arrodillarte como se arrodilla el esclavo, ni de llamarte amigo de tus enemigos

Nunca dejas de acusar a ninguno de tus prójimos

Nunca dejas de negar que eres humano,

ni de abrazar tu humanidad,

incluso entre sus monstruos.

El guerrillero de la segunda mitad del siglo XX, armado, desarmado, muerto, traicionado, monetizado, se modela en el crístico Ernesto Che Guevara, y, a un tiempo, en la desesperanza, en el reniego de la lucha armada y sus ídolos:

Fue la época en que se alzaron las guerrillas en todo el mundo

Yo me alisté con los guerrilleros en seguida

Nos fuimos a comenzar la lucha en las montañas

Luego bajamos como arañas sobre el enemigo

Volvimos a subir

Fue un subibaja que duró 10 años

hasta que fui hecho prisionero

Me pusieron en una mazmorra del demonio

Me mantuvieron 50 años a pan y agua

Lo que sigue es un sueño infernal

$\cdots$

Nos hemos vuelto locos de ver viajar por el espacio 
millones de ataúdes a la deriva cubiertos con banderas multicolores ("La sombra del guerrillero")

La salvación mediante la supervivencia implica la elitización porque, a diferencia del sujeto común, la gente inteligente piensa inteligentemente las mismas incidencias cotidianas que experimenta aquél. No obstante, formulando otra antinomia, Goldemberg recusa la elitización:

Lo castizo — no importa cual sea la casta

ni el país donde se encuentre-

no permite lo judío.

Los castizos siempre verán lo judio

solo como lo judio,

jamás como lo castizo.

Cuidémonos los judíos

de nuestros compatriotas castizos

y de nuestros castizos judios.

A esta advertencia la sobrevuela el epígrafe del poema citado ("Casticismos”), cuyo autor es José Puente Egido, que alerta respecto "a toda minoría selecta y cerrada que, con su inteligencia, laboriosidad y perspicacia, practique una endogamia exclusivista”, sin advertir que ésta ha sido una de las causas de la permanencia de la nación judía sin territorio.

La manía bélica se prolonga en los conflictos armados, genocidios y desgracias humanitarias del siglo XX y principios del actual, que han coadyuvado a los incontrolables éxodos de poblaciones del África, Medio Oriente y América Latina, y al bobo amurallamiento post muro de Berlín: tanto luchar por su caída para que casi enseguida se erigiesen otros. El costo de los éxodos lo seguiremos pagando durante lo que resta de este siglo de desazones en los mejores y más humildes comederos, pero paralelamente gozaremos de sus beneficios, entre ellos el de 
la exogamia, que determina que nuestros organismos y nuestras economías sigan funcionando.

Sólo nos consuela, según el chepeniense, la popular certeza de que ricos y pobres nos igualaremos bajo tierra, y de que, además, una compañía de seguros cubrirá el precio de morir, y los servicios de paisajismo aliviarán la pesadumbre de quienes visiten nuestras tumbas.

La muerte recorre el Libro de principio a fin. El de Chepén la toma como una visita antipática aunque obligatoria. La muerte nos alivia de la vida, nos despena, nos beneficia. La muerte se aparece en sueños que nos visitan más y más a menudo conforme avanzamos en la línea quiromántica. Goldemberg utiliza un epigrama gnómico para, con el debido respeto, exorcizar a la Parca y mantenerla a raya:

En el país de los muertos

la vida es rey.

Lo saben los que viven

con la esperanza del muerto.

En el país de los vivos

la muerte es rey.

Lo saben los que mueren

con la esperanza del vivo.

El Libro es un próspero ejercicio del diálogo. Así lo atestigua el epígrafe de Luis Hernández: "Una forma de escribir poesía es vivir epigrafiando.” El chepeniense epigrafía a discreción en Diálogos conmigo y mis otros. Epígrafes y poemas conversan, polemizan, disienten. Belli, que no escapó de la epigrafiada, reflexiona al respecto: "Son palabras, frases de otros, que manipulan febrilmente las puntas de mis dedos." El Libro deviene un multiloquio, un crucigrama parlante donde el lector se topa con un humor oblicuo que, según Ribeyro, es signo de inteligencia en la vida y en la literatura. 
Uno de los múltiples talantes de Goldemberg es el del pícaro, siempre huyente, de los tiempos modernos. La picardía fortalece, ahonda el poema:

Me fui a vivir en casa de familia

Por un tiempo bastante prolongado

me tratan como a hermano

La primera semana me sacan a pasear en auto

Las colinas me dan escalofríos

Por fin llegamos al Mar Muerto

Al mes me encamo con la hija

La madre se abalanza sobre mí cuchillo en mano

Hago maletas y abandono barco ("Itinerario")

El escritor que epigrafía corre el riesgo de que los epígrafes sean mejores que su texto. Se reta a sí mismo a desatar una esgrima entre cielos e infiernos. El de Chepén no aspira ni al triunfo ni a la derrota sino más bien a un tenso equilibrio entre lo suyo y lo de sus convidados. Alcanza el éxtasis que sólo se logra con el pensamiento, la meditación, la música, la guerra, el deporte.

Si me preguntan con cuál poema me quedo, respondo que me quedo con el Libro.

La belleza, como el diablo, está en los detalles, pero no es enemiga de la abstracción. El chepeniense se aleja del dialecto, pugna por universalizar su lenguaje, por construir una saga en lugar de una colección de textos más o menos ordenados: recurso imprescindible para manejar los grandes temas que confluyen en el Libro.

Goldemberg ejerce la claritas que demandó Umberto Eco al decir que en los años setenta del siglo pasado todo aquello que fuera oscuro debía de ser bueno. Claritas cuya demanda se atribuye a Einstein: "Every thing should be made as simple as possible, but not simpler." Y también: "If you can't explain it simply, you don’t understand it well enough." Justamente en 
aquel not simpler radica el misterio de la escritura, porque al existir de facto lo complicado, quien no lo aborda se queda en la lírica.

El chepeniense se torna provocador: "Escribir un poema después de Auschwitz es un acto de barbarie. Después de Auschwitz toda cultura es inmundicia” (Theodor Adorno). A semejante predicado apodíctico Goldemberg replica con "Los dados eternos" de Vallejo, escrito antes de Auschwitz, y con "Escribir un poema después de Auschwitz", texto suyo que niega el imperativo categórico de Adorno y que, al llevar el epígrafe extraído de "Los dados eternos" de Vallejo, relaciona la muerte del Nazareno con Auschwitz:

\section{Ironías de la vida: \\ al carpintero Jesús \\ lo clavaron en la cruz.}

A la antinomia subyace el enigma, el misterio, el not simpler, y el reconocimiento de que el scriptor no entiende bien y que, por lo tanto, su discurso contiene regiones oscuras, comenzando con la obsesión judeocristiana de un Dios macho, omnisciente, todopoderoso, capaz de obrar milagros, arrasar naciones enteras o dejar que sean arrasadas:

\section{Está muy bien eso de Dios \\ y Su libre albedrío \\ pero ¿por qué dejar a las víctimas \\ en manos de sus verdugos?}

La respuesta a tal pregunta se induce del concepto de la Verdad de los hechos humanos (y de los apóstoles) esbozado líneas arriba, en cuanto que ella es el producto de factores que para la ética eudemonista resultan inaceptables, como el simple hecho de que la evolución animal y humana se basa, hasta cierto punto, en devorarse y matarse los unos a los otros. 
¿Seremos capaces, como reclama el de Chepén, de reducir al mínimo la enfermedad de la

guerra y de la estupidez así como hemos reducido la incidencia de ciertas enfermedades? Acaso sea necesario extender el razonamiento de Freud en el sentido de que la salud debe compensarse con una dosis necesaria de enfermedad, para decir que la paz universal debe equilibrarse con una dosis necesaria de violencia. Goldemberg parece inclinarse por ello al decir en "Mail interplanetario":

infierno y paraíso pasan

a ocupar el mismo espacio.

Mejor mudar a los humanos de planeta, construirles casas, parques y colegios.

Todo lo humano es contingente

y el gasto saldrá a largo plazo más barato.

¿Sonríe la ética tras la máscara del Libro? Sí. Pero es una ética porosa, atravesada por el bien y por el mal, donde alternan múltiples contrarios en la coyuntura existencial del demiurgo.

No obstante que el mejor poema del Libro es el Libro, no puedo evitar la inclusión del brillante "Soneto inexacto del judío peruano y viceversa", compuesto para refutar el epígrafe donde Carlos Pellicer reclama que Dios nazca "un día sobre estas tierras locas de mi América":

Por Dios, Jesús, ni en sueños se te ocurra

nacer en mi otra tierra prometida.

Te lo ruega este judío de rodillas.

Lo mismo este peruano que me zurra

por hijo de camello. No, ;de burra!

De burra ofertada a tu cruz de palo

con que me zurra este judio, en vano,

por hijo inexacto de camello y burra. 


\begin{abstract}
Jesús, no oigas al vate que te invoca
desde el abismo de su ser cristiano

a que nazcas sobre estas tierras locas.

Por el Dios de Abraham de ti me fío

que no le ofrendarás a mi peruano

lo que con creces le has dado a mi judío.
\end{abstract}

Con un "Nací en los clavos de Jesús" comienza "Inventarios", en Hombre de paso, sección del Libro que guarda semejanza con la pena de Martín Fierro:

\author{
Viene el cuerpo \\ de hundir sus ojos tristes \\ de irse amontonando \\ en la carrera \\ de cavar exactos días \\ Es que el cuerpo no conoce \\ muertes \\ hasta que sale a jugarse \\ la vida.
}

$\mathrm{O}$ antes, en el mismo poema:

y luego nos acuestan sobre un nicho

para decirnos:

Duerman tranquilos

aquí no sube la marea

Es en vano: estoy por decirme

pero me tengo en la punta de la lengua 
Es en vano: aquí me empieza la vida

y voy de paso

Fierro y Goldemberg son almas errantes, hombres arrancados de su pago, víctimas de una nostalgia insoluble. El gaucho por la desgracia de su destino; Goldemberg por la estafa de la existencia. El errabundo

\author{
Entonces se mezcla con los hombres \\ Va moldeando su frágil maquinaria a tropezones \\ se hace funcionario \\ lo llenan de papeles \\ $\cdots$ \\ Me niego a pagar futuras cuentas \\ ahora que soy una memoria \\ Convertido en cifra y cementerio \\ voy distribuido \\ en cada puño de tierra
}

Apartado de la cosmocracia y de los poderes locales, el chepeniense, a fuerza de pensar —es el pensar de los judíos lo que desea exterminar el antisemita-, edifica una arte poética irreductiblemente partidaria del amor mortis, contraria del amor vitae y del amor deis. Se configura pues una persona ácrata, atea, judeocristiana, eudemonista, y cínica en el sentido griego. De allí la validez del poema "Arte poética", cuyo gozo dejo al asalto del lector, aunque ello no me impida traicionarlo con un fragmento:

El río traza un camino no se sabe si de sol o de sombra

el sueño empuja las palabras sobre las aguas

que corren ausentes a quien escribe

y quien escribe las mira correr

con ojos que como el sol rehúsan hundirse 
La aparente apostasía del chepeniense se opone a la intimidad judaica. Luego de citar a Dios, que ha caído en la redada epigramática, nos entrega "Deuda saldada":

\author{
Señor: \\ La curiosidad de una hermosa \\ y cristiana dama \\ por mi púber pene circunciso \\ me hizo conocer \\ por la primera vez \\ las delicias de Tu Paraíso
}

Huidizo Lazarillo o Buscón que sin embargo, con las maletas listas por si acaso, puesto que "la astucia es hija de los destierros", declara:

Lo que es yo: no те тиеvo de aquí

ni aunque me pongan una pistola en el pecho

Lo que yo quiero es quedarme

donde tengo los pies

Defender mi metro cuadrado

como Leónidas el Paso de las Termópilas

El predicado que ofrece Goldemberg sobre el cristianismo resulta, a mi parecer, bastante acertado: "Una mezcla de paganismo romano con ciertos rasgos de monoteísmo judío." Por contraste, en sus reflexiones, a veces y en buena hora juguetonas, el apóstata de Chepén aparenta estar seguro del judaísmo ecuménico, bien descrito por Baron (I, 13) a pesar de mi traducción:

En relación a lo que el "fin de los días" traerá acarreado, las opiniones varían. Algunos creen que aun en la edad mesiánica el pueblo judío retendrá su identidad, tal como lo harán otras naciones, con la única diferencia de que todas las naciones profesarán el 
mismo credo. Otros, a quienes podemos llamar judíos cosmopolitas, sueñan con la mixtura de todas las naciones en una humanidad uniforme, igualmente bajo la dominación de un credo, el judío. Luego el pueblo judio desaparecerá, porque habrá cumplido su deber y también porque, en cierto sentido, todos los hombres habrán devenido judíos.

Goldemberg no da respuestas seguras. Más bien nos incita a compartir misterios, entre ellos el del Dios judeocristiano, cuya parte judía se torna aún más complicada que su contraparte cristiana. ¿O acaso estamos hablando de una misma idea que se persigue a sí misma? El horror histórico podría reforzar dicha alternativa:

\title{
Grande ha sido el salto \\ de la hoguera española \\ a la cámara de gas.
}

"Yo soy el que soy. Así se le define Dios a Moisés (Éx, 3: 14) cuando éste le pregunta qué teónimo ofrecerá a los hijos de Israel cuando le pregunten cómo se llama el Dios de sus padres. Goldemberg acepta la existencia de Dios como un personaje incansablemente escrito, tanto como lo son los tópicos de la peruanidad y del judaísmo:

\author{
El judío es tan triste \\ como el murciélago \\ El peruano es más triste \\ que el gato \\ El judio es menos triste \\ que el Zar \\ El peruano es el más triste \\ de todos \\ El judio es triste
}




\section{El peruano es muy triste El judío es tristísimo}

La tierra prometida del chepeniense es el país donde queda Chepén, pueblo fantástico, pueblo del padre judío, de la madre peruana. Como le sucedió a Pablo Guevara en los cinco volúmenes de La colisión, Goldemberg se muestra tan impresionado por la agudeza de sus otros, que renuncia al ego y a la voz propia, apabullado por la conversación de una gran familia cuyos miembros, gracias al ociosiloquio, aparecen, desaparecen, hablan, callan, caen, se levantan:

Por no buscar mi propia voz

- temor a no tener qué decir-

he escrito a través de otras voces

como con mordaza.

Voces de personajes que no saben escribir.

Personajes que escriben con la voz del escritor.

Nunca con la voz del yo.

Es mortal el temor de no tener qué decir desde el yo. ("Estilos")

Ultraviolento, celoso, como para desterrar los epígrafes, se alza el homenaje a la madre peruana y al padre judío:

Con nada, lo que se dice nada,

rosa de la pasión, olvido trunco,

jugada de la simpática muerte. Es el amor,

que no reconoce ni a su señora madre,

puta como ella sola, ¡ni le enseñen el billete!

No vaya a ser que nos ponga a trabajar 
estirando la mano, como un cristiano.

Decía: la suerte fenecida en la cartera y

el ojo del hijo en la herencia que nunca dejó el padre.

Seguramente llorará, pero no por el viejo,

seguramente. Ni este abrirá el paraguas,

seguramente. Ni hablar:

¿En una ciudad donde nunca llueve?

Entonces para qué tanto impermeable,

para qué tanto jebe en un cache entre dos

lápidas que las pusieron sin nombre.

$\cdots$

Hay muertos que vuelan sin freno y la vieja

duerme. En su cueva de mierda, duerme.

Duerme su muerte: La hija del padre

que se murió en la madre. ¡Cuánta tristeza!

¿Qué tal cojuda tristeza

de no poder parir a la madre!

"Genealogías" sigue su curso con ternura apenas desbocada, que evoca Mentadas de madre, el poema hecho libro de Pablo Guevara. A los padres y madres de Pablo Guevara y de Isaac Goldemberg los une la sustancia cronística de sus versos, inconfundiblemente peruanos y breñenses para ser más preciso, porque ambos vivieron en el limeño distrito de Breña.

Antes que un ego scriptor bipolar, lo que se configura en el Libro es un demiurgo que aparenta no saber quién es y, así disimulado, crea universos fractales con la singularidad de que el todo es la suma de partes iguales al todo, pero muchas de ellas son irreconciliables respecto de las otras, como en el teorema de la Verdad que propuse al principio de estas líneas. En tal panorama, el epígrafe de Bukowski cae, por decirlo dulcemente, como anillo al dedo: Es imposible que a nadie no le guste el olor de su propia mierda. Goldemberg lo exorciza: 
Los deseos más oscuros

arrojan luz sobre la oscuridad

si uno sabe reconocerlos

En el demiurgo del Libro se conjugan la Bestia Humana, el Dios con o sin nombre encarnado en nosotros, los viejos Armuz y Arimám, la lucha entre el bien y el mal repetida en la cábala. Dios es un cuerpo de proporciones gigantescas: noventaiséis millas de altura y noventaicuatro millas de ancho. Siendo originalmente andrógino, luego dividido en dos, la parte masculina deviene el Mesías, y la parte femenina el Espíritu Santo. Más acá de esta cabalística medición y concepción de la divinidad, en el Libro se acentúa la doctrina dualista del Dios iracundo del Antiguo Testamento y del Dios de los evangelios, todo amor y misericordia; dualismo que se cuaja en el amor a la vida y en la atracción arguediana por la muerte, "con el dedo en el gatillo" en "un ataúd de hierro.” El gozo de vivir, empero, es intenso en el Adán del Nuevo Testamento, que reclama la vida que habrá de perder y se pregunta:

¿Se nos hará duro este pan

el día que ya no lo toquemos?

¿Podrán oír nuestras visiones

el día que ya no las callemos en voz alta?

La enciclopedia universal que soñaba Borges, o en la que el sueño de Borges se soñaba, la luz que vislumbramos cuando envejecemos, existe ya en el ciberespacio: todo lo que imaginamos sucede ahora, y si imaginamos algo que no sucede pero tiene valor, se produce y se nos ofrece en el acto. Goldemberg ha tenido el celo de imaginar lo que no existía antes, el Libro, que, como buena obra o buen obrar, se disfruta toda la vida, tentándonos socarronamente desde el anaquel, o abierto como una flor de primavera en nuestras manos, bajo la buena luz del sol, o bajo el humilde amparo de un diodo. 
Al placer intelectual de leer el Libro se suma la sensualidad de hurgar en sus sabrosos versos de amor puro, perverso, nuestro, cincelados por un rimador trejo. La sombra de la muerte se equilibra, se disuelve en rutas entreveradas. El hacedor humano se ha encarnado en el chepeniense, que es el que es y será en sus libros. Una vez más, el hombre ha creado a Dios.

\section{Bibliografía}

Goldemberg, I. (2018) Libro de reclamaciones. Antología Poética Personal (19812016).España: Los Papeles de Brighton. 